\title{
Epigenetische Prozesse bei Suchtentwicklung
}

Suchterkrankungen sind multifaktoriell verursachte Störungsbilder, bei denen neben psychologischen und sozialen Einflüssen auch wesentliche neurobiologische Mechanismen ursächlich sind. Den sogenannten epigenetischen Mechanismen, wie der Beeinflussung der Chromatinstruktur und der Methylierung der DNA, kommt dabei eine besondere Bedeutung zu, da durch sie auf molekularer Ebene Umwelteinflüsse integriert und gespeichert werden können und dadurch eine direkte Beeinflussung der Regulation genetischer Netzwerke stattfinden kann. Für die Entstehung und Aufrechterhaltung von Abhängigkeitserkrankungen sind dabei verschiedene neuronale Regelkreise von großem Interesse, vor allem das Belohnungssystem, das eng mit der zerebralen Energieregulation und der Stressachse verbunden ist. In den letzten 15 Jahren konnten wir zeigen, dass epigenetische Mechanismen an der Regulation dieser neuronalen Systeme beteiligt sind und dass sowohl stoffgebundene als auch stoff-unabhängige Abhängigkeitserkrankungen mit Störungen dieser epigenetischen Regulation einhergehen.
So konnte beispielsweise für verschiedene Suchterkrankungen (Tabakabhängigkeit, Alkoholabhängigkeit, pathologisches Spielen) gezeigt werden, dass sich die Methylierungsmuster in der Promotorregion des Dopamin-2-Rezeptor-Gens signifikant von gesunden Kontrollen unterscheiden. Weitere Untersuchungen belegen die Bedeutung von Genen der Appetitregulation wie POMC und Leptin, aber auch Gene aus dem Alkoholstoffwechsel wie die Acetaldehyddehydrogenase-2 können (fehl-) reguliert werden. Dabei zeigt sich eine komplexe Interaktion zwischen genetischen Faktoren einerseits und Umweltbedingungen andererseits, die sich in der Veränderung der epigenetischen Regulation zahlreicher Gene niederschlagen kann.

Diese und andere Ergebnisse deuten darauf hin, dass epigenetische Mechanismen eine Rolle in der Entstehung und in der Aufrechterhaltung süchtiger Verhaltensweisen zukommt. Diese Forschungsergebnisse könnten helfen, sowohl für die Prävention wie auch für die Therapie spezifische Biomarker zu entwickeln und so eine individualisierte Behandlung von Suchterkrankungen möglich zu machen.

Interessenkonflikte

Keine

\section{Autor}

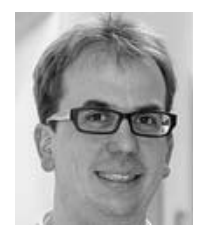

Helge Frieling Klinik für Psychiatrie, Sozialpsychiatrie und Psychotherapie, Medizinische Hochschule Hannover

\section{Korrespondenzadresse}

Prof. Dr. med. Helge Frieling

Klinik für Psychiatrie, Sozialpsychiatrie und Psychotherapie

Medizinische Hochschule Hannover

Carl-Neuberg-Straße 1

30625 Hannover

frieling.helge@mh-hannover.de 